\title{
An Exploration on the Culture Compensation in Publicity-oriented Chinese-English Translation of Jiangxi Enterprise Websites
}

\author{
Guilan Liu \\ School of Foreign Languages \\ Nanchang Institute of Technology \\ Nanchang, China 330099
}

\author{
Juanping Shao \\ School of Foreign Languages \\ Nanchang Institute of Technology \\ Nanchang, China 330099
}

\begin{abstract}
This paper takes enterprise website publicityoriented Chinese-English translation of Jiangxi Province as an example to explore the cultural default compensation strategies to website Chinese-English translation, with a view to helping enterprises overcome cultural barriers, to bettering crosscultural communication and to improving the international competitiveness of enterprises.
\end{abstract}

Keywords-enterprise website; publicity-oriented ChineseEnglish translation; cultural compensation

\section{INTRODUCTION}

With the popularity of international information network technology and the rapid development of e-commerce, it has been a general trend for enterprises to take advantage of the Internet for electronic transactions. Especially, the strategic conception of "The Belt and Road" provides the best opportunity for the development of Jiangxi Province. Therefore, in order to shape the development of corporate image of internationalization, to enhance brand awareness, to actively explore overseas markets and to improve the international competitiveness of enterprises, it is imperative for major enterprises in Jiangxi Province to have an English website on the global Internet which is in line with international standards. This is a platform for customers or investors to get information quickly, and it will facilitate the convenient and effective communication and exchange among customers, suppliers, and partners in different regions and among different cultures.

\section{Cultural Default AND Translation COMPENSATION}

\section{A. Cultural Default}

Cultural default is the omission of the cultural background knowledge shared by the author and the intended reader when communicating. The content of cultural default is what is gradually formed and widely accepted in the long - term social development where the

This paper is supported by Humanities and Social Sciences Foundation for Universities of Jiangxi Province (yy1543) \& Jiangxi Provincial Social Science Foundation (15WX207) two communicating parties live together and it is related to the cultural background outside the text. They may be displayed in customs, habits, religious beliefs, or comportment standardization. Translation is a cross-cultural communicative activity involving two different languages and cultures. It is the dialogue and communication between the translator and the original text, between the author and the target language readers, and as a result, it involves dialogue and collision between two different cultures. Therefore, the cultural background knowledge which is obvious to the readers of the original text constitutes the cultural default component for the target readers. The process of translation is to build a bridge of cultural communication. So, in the process of translation, we must follow certain norms and adopt effective translation strategies to achieve cross-cultural communication purposes.

\section{B. Compensatory Translation}

Compensation translation was put forward in 1960s, not until the late 1980s did scholars of translation studies begin to define the concept of compensation in a more rigorous way. This situation is not in conformity with the role that compensation translation plays in the field of translation. Wilss, a German translation theorist, said the debate about literal translation and free translation had given way to the following questions: "How should translators give consideration to both the source language and the target language to achieve textual communicative synchronization? $\mathrm{He}$ should also pay attention to how to compensate for structural differences within and outside the language, and how to compensate in the micro context and in the macro context." (Wilss, Wolfram: 2001) In the process of solving the problem of untranslatability, Chinese and Western scholars turn their attention to the study of translation compensation.

George Steiner's compensatory translation theory can be summed up to be: translation loss runs through the whole process of translation and the translator is the primary cause of translation loss; the compensation strategy should aim at the quality rather than the increase of the words. While noting the contribution of Steiner, we should also note that he has too much emphasis on the subject's (translator's) 
dereliction of duty, but ignores the insurmountable cultural barriers in the primitive language. One the other hand, Peter Newmark's compensation theory is essentially on the basis of text functions and as far as Newmark is concerned, different compensation measures are adopted for different texts and functions and text functions are divided into expressions, messages, and appeals. (Newmark, Peter: 2001)

Hervey and Higgins propose four forms of compensation: the first one is compensation in kind, that is, in the target language text, the equivalent of the original text is used to reproduce the original effect; the second one is compensation in place, that is, the translated text reproduces the same effect in a different position from the original text; the third one is compensation by merging, that is, the translated text combines multiple features of the original text; the forth one is compensation by splitting, that is, the translated text combines the meaning and features of the original text with the short phrases in the longer sentences of the version. In particular, the two authors emphasize that these forms can be used simultaneously and are not mutually exclusive. (Ma Hongjun, 2003:37-39)

The cultural function of translation determines that translation plays an important role in the construction of a foreign culture and has a profound influence on the target culture. In order to achieve a coherent understanding of the target text, the translator must carry out cultural compensation so as to enable target readers to enjoy the cultural exploration. From the point of view of cultural communication and the expectation of the target readers, in the process of compensation for cultural default, the translator should try his best to make the target readers appreciate the exotic atmosphere and cultural information contained in the original text. Therefore, in translation practice, the translator should carefully examine the cultural elements in the original text, and according to the specific circumstances of the original text and the principle of perfectly fulfilling the cultural compensation, flexibly makes the correct compensation strategy.

\section{CULTURAL COMPENSATION STRATEGY OF PUBLICITY-ORIENTED CHINESE-ENGLISH TRANSLATION}

After visiting 102 websites in Jiangxi Province, we have found that many large and medium-sized enterprises in Jiangxi province don't have their own English Websites. Altogether, we surveyed a total of 29 Jiangxi's industrial enterprises, and 18 of them are machinery enterprises, 4 of them are solar energy enterprises, and the rest 7 are tool enterprises. Among the 29 Jiangxi's industrial enterprises, only two have the publicity-oriented Chinese-English translation websites, which occupies only $6.8 \%$ of the 29 enterprises, and both of them are machinery enterprises. That is to say, none of the solar energy enterprises or tool enterprises has publicity-oriented Chinese-English translation website. And we surveyed a total of 19 consumer goods companies in Jiangxi province, but only one of them has publicity-oriented Chinese-English translation website, which accounts for 5.2 percent. Also, we surveyed 18 Jiangxi agricultural enterprises totally, and only one of them has a propaganda translation website, which accounts for 5.5 percent. Among the 21 raw material enterprises surveyed in Jiangxi province, four of them have a foreign language translation websites, which accounts for $19 \%$. Even for the 14 tourist attractions and tourism companies in Jiangxi province, only 5 of them have a publicity-oriented ChineseEnglish translation website, which occupies $35.7 \%$ of the total. Meanwhile, a large number of mistranslations have appeared in the translation of Jiangxi enterprises' English language websites.

In view of the huge differences of cultural backgrounds, ideology, language expression and thinking mode between China and foreign countries, and for the effective transmission of information, we have analyzed a lot of specific examples and put forward the following three translation strategies of cultural compensation for enterprises' publicity-oriented Chinese-English translation websites to make the website play the function of external publicity and avoid the misunderstanding.

\section{A. Translation Strategy of Rewriting}

"Rewriting is the most thorough variation measures to solve the problem of word order and expression level, and also one of the best means to guarantee the readability of the target language, which is obviously the most convenient to produce the advantage of the translation. "To fulfill the requirements of native English expression at a higher language level, to increase the effectiveness of the communication, strengthen the appeal, and meet the demands of readers, it is necessary for translators to rewrite the original texts to make sure the translation more in line with the habits of the target language and the spoken language of the readers.

Due to cultural differences and the limited ability of translators, it is inevitable to misinterpret in the process of making publicity-oriented English websites. Many foreign language translation issues involve the cultural level, so when translating the enterprise websites, it is important to consider the audience's cultural background. However, many large enterprises in Jiangxi province are not aware of the target readers of their publicity-oriented English websites and have generated cultural mistranslations. For example, the homepages of the websites are filled with the titles and logo of the enterprises, and the lengthy corporate reputation reports. But in fact, the visitors will not care about these unnecessary contents. When translating these contents, a brief explanation will be ok. Let's take a look at a passage from the website of Jiangxi Sanchuan Group Co. Ltd:

Products have got titles successively as Chinese Famous Brand, National Inspection Exemption; National Customers satisfied Product, Ministry of Construction Popularizing Product and Water Association Popularizing Product. The registered trade mark "San Chuan Brand" is the only Chinese Famous Brand cognized by the State Administration for Industry and Commerce in domestic water meter industry.

Obviously, this is a lengthy passage to list out the corporate awards and it is to tell readers that the company is so excellent. However, due to cultural differences, overseas customers do not necessarily know the specific meaning of 
these awards. The negative effect will make the customers feel that the enterprise style is slow and inefficient, which can't help to achieve the expected publicity result. These contents should be simplified as far as possible, simply by expressing the meaning of these awards, namely, the products enjoy high quality and the enterprise have high management level. The following rewrite will be better:

San Chuan has received dozens of honorary and professional titles conferred by national and provincial and city authority due to its high- quality products, advanced management, and outstanding profits.

In the process of translation, translators should base on different cultural background, consider from the perspective of conforming to the target language readers and respect the language and cultural differences between Chinese and English, properly adjust the structure and information of the original text to improve the acceptability of the target language readers and to achieve the intended purpose of the translation.

\section{B. Translation Strategy of Omitting}

"Omitting has positive effects such as semantic ellipsis, rhetoric expresses, stylistic coloring, language structure improvement and better communication. The basic norm of omission is: to facilitate a comprehensive transformation of meaning; to help the moderate optimization of the language structure, so the so-called 'moderate' refers to the flexible correspondence with the original language and to help with the acceptor and the recipient's aesthetic participation." To achieve the purpose of better communication, for the information that has special value in primitive culture but may be meaningless or just increase readers' burden and have no practical information in the target language culture, we should adopt the translation strategy of omitting. The content of the omitted translation may be a word, a sentence, a paragraph or a few texts. Sometimes, in the pursuit of literary grace and for language aesthetic effect enhancement, some texts make use of some four word structures, parallelism sentences and propagandas. Under such circumstances, we can adopt the translation strategy of omitting. There is a good example in the introduction of BaiLudong Academy. The Chinese introduction includes the following information (http://www.chinalushan.com/resort/detail.php?sty=1\&id=5):

BaiLudong Academy, also called Mount Lu Academy in Jiangxi, is one of the Four Classical Academies in China. Bailudong Academy has formed a set of comprehensive management system, which consists of cultural relics management, teaching, academic research, tourism and forest - garden construction.

Let's see the following English introduction on the enterprise's official website:

Bailudong Academy was built in 940 AD. Zhuxi, the great educator of the South Song Dynasty, turned the place into Bailudong Academy, which rivaled the other three famous academies in China. It was a school for some famous people reading there.
As we can see, the Chinese introduction on the official website is much more complicated, and also mentions the history and development of BaiLudong Academy, but to avoid lengthy information, the English introduction selectively retains and extracts important information to help foreign visitors understand the history of the Academy. By this way, the translation strategy of omitting can make a deep impression on foreign tourists, and is conducive to the publicity of scenic spots.

\section{Translation Strategy of Equivalence}

Equivalence is regarded as the basic conventional means of translation. But in fact, because of the great differences between Chinese and English, such as language structure, word order, expression mode, modality and deep meaning, formal meaning and so on, "equivalence" is only a relative concept, so the adjustment is essential.

On the official website of Zhengbang Group Co., Ltd, president of the enterprise adopted a famous sentence from the Book of Changes in a speech, which is translated to be:

As Heaven's movement is ever vigorous, so must a gentleman ceaselessly strive along.

But in a book edited by Professor Li Changquan at Beijing Foreign Studies University, it is translated to be: "As heaven maintains vigor through movements, a gentle man should constantly strive for self-perfection. As earth's condition is receptive devotion, a gentle man should hold the outer world with broad mind." The general meaning of classic saying is that the gentleman should know how to follow the heavenly law, and how to bear and tolerate. Obviously, the translation of Professor Li Changquan takes cultural background into consideration, which helps the target readers to understand the exact meaning better.

From this example, we can see that in the translation of classical Chinese sentences, the translator should first understand the cultural background of original text, because it will help to avoid cultural misunderstanding. Some of the websites give us strong evidence. On the official website of Longhu Mountain Resort, there is a brief introduction about Guigu Cavern :

Around Guigu Cavern (Guigu was the originator of Political Strategists), there is Sunbin Stockade (Sunbin, Guigu's student, was a famous militarist), Millennium Maidenhair tree, Ancient City Wall and other sights.

Guigu is also called Wang Chan ancestor, the forefather of the Political Strategists (in the Warring States Period, 475 BC - $221 \mathrm{BC}$ ) and famous educator in the Spring and Autumn Period and the Warring States period. Sunbin is under the tutelage of Guigu and he is a great militarist during the Warring States Period and the writer of Sun Bin's Art of War. Both Guigu and Sunbin are well-known historical figures in China. But these two names contain the background of Chinese culture and history, and the target language readers don't know much about Chinese history and culture, if the translator simply lists their names, without further explanation, foreign tourists may feel confused, so there is no way to understand its value and historical culture. 
As a result, in the process of translational action, the translator can add the "Guigu" and "Sunbin" identity explanation to compensate for the potential cultural and historical information, which will help target readers, interpret the latent cultural connotations of the original text and achieve the purpose of cross-cultural communication. If we act in accordance with Chinese thinking mode, it will inevitably cause the translation text to pile up and the semantic expression isn't quite true to the original. In short, it means "saving words but not saving meaning". (Zhang Ji, 2001: 21-22)

\section{CONCLUSION}

Since the enterprises want to promote their products to foreign markets, we should pay attention to the publicityoriented Chinese-English translation websites. The website is the quickest, most convenient and direct way to display the profiles, qualifications, and image of an enterprise. As a specialized translation, website translation requires the translator's own ability to live up to the standard of translation. The publicity-oriented Chinese-English translation should establish a "reader- centered" concept and intercultural communication awareness throughout the translation process. At the same time, translators need to broaden their knowledge, renew their translation theories and methods, improve their professional level and cultural accomplishment, and mold good professional ethics. Therefore, in the compensation process of cultural default of target readers, translators should try their best to make the target readers get the cultural information of the original text, but not to make the target readers lose the opportunity to enjoy cultural exploration because of the excessive compensation. That is to say, we should not only take care of the original style and be faithful to the original, but also consider the translation of the operability and keep in line with the target language expression habits. This requires translators to be familiar with their national language and culture that they want to communicate, to improve their language's ability of application and expression, and finally to achieve the standard of "faithfulness, expressiveness and elegance".

\section{REFERENCES}

[1] Wilss, Wolfram. The Science of Translation: Problems and Method [M]. Shanghai: Shanghai Foreign Language Education Press, 2001.

[2] Ma Hongjun. Classification and application of translation compensation. [J]. Foreign Languages and Their Teaching, 2003, (10):37-39

[3] Newmark, Peter. A Textbook of Translation [M]. Shanghai: Foreign Language Education Press, 2001.

[4] Zhang Jipei. On the necessity of trimming the original text in publicity-oriented Chinese-English translation. [J].Shanghai Journal of Translators for Science and Technology, 2001, (3):21-24. 